\title{
Geomechanical characterisation of massive rock for deep TBM
} tunnelling

\author{
M.C. Villeneuve \& M.S. Diederichs \\ Department of Geological Sciences and Geological Engineering, Queen's University, Kingston, Ontario, \\ Canada \\ P.K. Kaiser \\ MIRARCO, School of Engineering, Laurentian University, Sudbury, Ontario, Canada \\ C. Frenzel \\ Herrenknecht, $A G$, Schwanau, Germany
}

\begin{abstract}
A combined geological and rock mechanics approach to tunnel face behaviour prediction, based on improved understanding of brittle fracture processes during TBM excavation, was developed to complement empirical design and performance prediction for TBM tunnelling applications in novel geological conditions. A major challenge of this research is combining geological and engineering languages, methods, and objectives to construct a unified geomechanics characterisation system. The goal of this system is to describe the spalling sensitivity of hard, massive, highly stressed crystalline rock, often deformed by tectonic processes. Geological, lab strength testing and TBM machine data were used to quantify the impact of interrelated geological factors, such as mineralogy, grain size, fabric and the heterogeneity of all these factors at micro and macro scale, on spalling sensitivity and to combine these factors within a TBM advance framework. This was achieved by incorporating aspects of geology, tectonics, mineralogy, materials strength theory, fracture process theory and induced stresses.
\end{abstract}

\section{INTRODUCTION}

Tunnel Boring Machines (TBM) are being used for tunnel excavation in deeper and tougher environments than ever before. Current TBM design and performance prediction methods based on empirical databases and lab scale and in-situ testing (Bruland 1998, Rostami et al. 2002, Rostami et al. 1996, Zhang et al. 2003) consider factors such as UCS, Brazilian tensile strength, joint characteristics (Barton 2000, Sapigni et al. 2002) and TBM specific index test values (CERCHAR 1986, Dollinger et al. 1999, Plinninger et al. 2003). These design methodologies can be successfuly applied to projects that fit within the realm for which the empirical databases contain a large amount of data. When attempting to apply these methodologies to novel conditions, such as in very hard, massive or foliated, unjointed rock at high stress, the nuances that are important under these conditions may be overlooked during TBM design.

Advances made to TBM performance prediction in massive rock consider rock mass fabric (Büchi 1988), but do not provide the necessary distinction between individual rock types and expected behaviour. A geomechanical characterisation system based on an investigation of the impacts individual geological characteristics have on rock fracture and TBM performance will allow engineers to more specifically predict rock response at the face to tunnel and stress geometry during TBM excavation.

Techniques used by geologists to characterise massive rocks, such as rock type classification, are applied to engineering problems to provide greater insight into the differences that are not revealed by conventional engineering methods, such as standard lab strength testing. The purpose of this paper is to present new approaches that quantify geological characteristics based on rock mechanics principles to improve rock behaviour prediction at the tunnel face.

\section{DEVELOPMENT OF A GEOMECHANICAL CHARACTERISATION SYSTEM}

A review of recent deep TBM tunnelling projects in the Swiss Alps has shown that, except for in a few extreme cases (Bonzanigo \& Opizzi 2005, Burkhard $\&$ Isler 2005), the geological prediction was similar to the rock actually encountered during tunnelling (Chopin 2005, Frei \& Breitenmoser 2005). The selection of appropriate excavation and support tools and techniques, therefore, critically depends on 


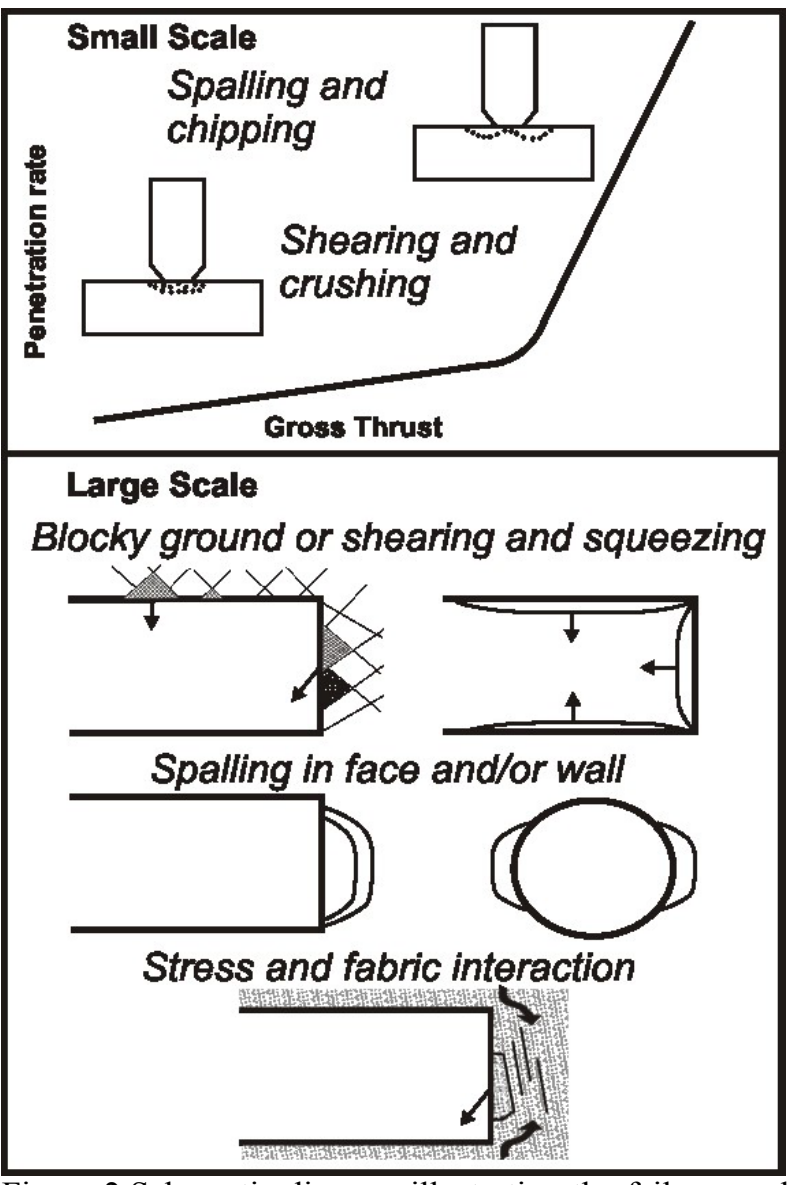

Figure 2.Schematic diagram illustrating the failure mode areas of focus. Top: schematic penetration rate vs gross thrust graph shows two separate processes during TBM cutter excavation: grinding at low thrust and penetration rate, versus chipping (a process akin to spalling) at high thrust and penetration rate. Bottom: tunnel cross sections demonstrate wall and face failure mechanisms; from top left: blocky ground resulting from discontinuities, squeezing due to shearing in low competence rock masses with respect to induced stress, spalling in the wall and/or face, depending on rock mass characteristics and induced stress geometry, and stress-fabric interaction inducing block formation and instability in the face.

All designations for low, medium and high, denoting relative impact on fracturing and spalling behaviour, are related to the cutter-rock interaction and face instability realm. Low impact indicates characteristics that are unfavourable to spalling, and high impact indicates characteristics that promote spalling. This characterisation only suggests sensitivity to spalling and fracture potential, since the manifestation of spalling during TBM excavation also depends on the interaction of the tunnel, anisotropy and induced stress geometries specific to each tunnelling situation.

\section{RELATIONSHIP BETWEEN THE CHARACTERISATION SCHEME AND GEOLOGICAL DESCRIPTION/HISTORY}

Testing and calibration of the geomechanical characterization is demonstrated by combining available geological, engineering and mechanical
Data Collection Interpretation for Behaviour

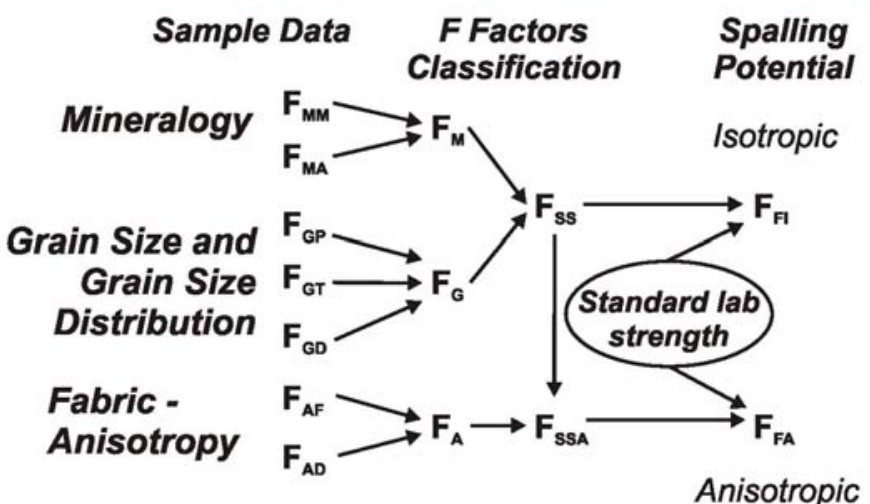

Figure 3. Characterisation schematic showing data collection, classification and combination to obtain fracture potential. Legend: $\mathrm{F}_{\mathrm{MM}}$ - mineralogy major; $\mathrm{F}_{\mathrm{MA}}$ - accessory minor; $\mathrm{F}_{\mathrm{M}}-$ mineralogy; $\mathrm{F}_{\mathrm{GP}}$ - grain size petrological; $\mathrm{F}_{\mathrm{GT}}$ - grain size tectonic; $\mathrm{F}_{\mathrm{GD}}$ - grain size distribution; $\mathrm{F}_{\mathrm{G}}$ - grain size and grain size distribution; $\mathrm{F}_{\mathrm{AF}}-$ fabric type; $\mathrm{F}_{\mathrm{AD}}$ - fabric scale; $\mathrm{F}_{\mathrm{A}}-$ anisotropy; $\mathrm{F}_{\mathrm{SS}}$ - spalling sensitivity; $\mathrm{F}_{\mathrm{SSA}}$ - spalling sensitivity with anisotropy; $\mathrm{F}_{\mathrm{FI}}$ - isotropic fracture potential; $\mathrm{F}_{\mathrm{FA}}-$ anisotropic fracture potential

Table 1. Description of geological characterisation factors

\begin{tabular}{|c|c|}
\hline Factor & Description \\
\hline$\overline{F_{M}}$ & $\begin{array}{l}\text { Mineralogy. Total and relative percentage of } \\
\text { major minerals, } \mathrm{F}_{\mathrm{MM}} \text {, such as quartz, olivine, } \\
\text { feldspar, calcite, amphibole, and pyroxene, and } \\
\text { total and relative percentage of accessory } \\
\text { minerals, } \mathrm{F}_{\mathrm{MA}} \text {, such as biotite, muscovite, garnet, } \\
\text { pyrite and magnetite, are weighted for their low, } \\
\text { medium or high impact on fracturing and } \\
\text { spalling behaviour. The combination of the two } \\
\text { results in a low, medium or high designation for } \\
\text { the mineralogy factor. }\end{array}$ \\
\hline $\mathrm{F}_{\mathrm{G}}$ & $\begin{array}{l}\text { Grain size and grain size distribution. Median } \\
\text { grain size, } \mathrm{F}_{\mathrm{GP}} \text {, grain size reduction due to } \\
\text { tectonic processes, such as subgrain formation } \\
\text { and grain boundary migration, } \mathrm{F}_{\mathrm{GT}} \text {, and grain } \\
\text { size distribution, primary or secondary resulting } \\
\text { from tectonic deformation, } \mathrm{F}_{\mathrm{GD}} \text {, are designated } \\
\text { low, medium or high, and are combined to result } \\
\text { in a low, medium or high designation for grain } \\
\text { size and grain size distribution impact on } \\
\text { fracturing and spalling behaviour. }\end{array}$ \\
\hline $\mathrm{F}_{\mathrm{A}}$ & $\begin{array}{l}\text { Anisotropy. Foliation type, } \mathrm{F}_{\mathrm{AF}} \text {, and foliation } \\
\text { dimension, } \mathrm{F}_{\mathrm{AD}} \text {, in combination as } \mathrm{F}_{\mathrm{A}} \text {, are } \\
\text { assigned a low, medium or high designation for } \\
\text { impact on fracturing and spalling behaviour. }\end{array}$ \\
\hline $\mathrm{F}_{\mathrm{SS}}$ & $\begin{array}{l}\text { Isotropic spall Sensitivity. } \mathrm{F}_{\mathrm{M}} \text { and } \mathrm{F}_{\mathrm{G}} \text { are } \\
\text { combined to determine the low*, medium or } \\
\text { high sensitivity to isotropic spalling. }\end{array}$ \\
\hline $\mathrm{F}_{\mathrm{SSA}}$ & $\begin{array}{l}\text { Anisotropic spall sensitivity. } \mathrm{F}_{\mathrm{SS}} \text { and } \mathrm{F}_{\mathrm{A}} \text { are } \\
\text { combined to determine the low*, medium or } \\
\text { high sensitivity to anisotropic spalling. }\end{array}$ \\
\hline $\mathrm{F}_{\mathrm{FI}}$ and $\mathrm{F}_{\mathrm{FA}}$ & $\begin{array}{l}\text { Isotropic and anisotropic fracture potential, } \\
\text { respectively. Standard lab strength values and } \\
\mathrm{F}_{\mathrm{SS}} \text {, for isotropic rocks, or } \mathrm{F}_{\mathrm{SSA}} \text {, for anisotropic } \\
\text { rocks, are combined to determine the fracture } \\
\text { potential of the rock, and normally manifests } \\
\text { itself as a reduction of the lab strength value, } \\
\text { representing excavation boundary strength: } \\
\mathrm{F}_{\mathrm{FI}}=\mathrm{F}_{\mathrm{SS}} \mathrm{X} \text { lab strength; } \mathrm{F}_{\mathrm{FG}}=\mathrm{F}_{\mathrm{SSA}} \times \text { lab strength }\end{array}$ \\
\hline
\end{tabular}

* 'Low' designations approach 1, while 'high' designations approach 0.45 
data along a length of tunnel and then dividing them into domains. The rock characteristics, behaviour and response to TBM tunnelling are compared and contrasted within and between domains.

\subsection{Geological Background}

The characterisation scheme is used to quantify the geology of a section of the Gotthard Base Tunnel (GBT) in the central Swiss Alps (Fig. 4). Samples were collected from the Southern Aar Granite (SAG), a unit of the Aar Massif located at the North end of the tunnel (Fig. 5). The Aar Massif is composed of a northern and southern gneiss zone of poly-metamorphosed basement rock, which underwent the highest grade of metamorphism, a core of Central Aar Granite (including the SAG), which underwent lower grade metamorphism, and metavolcanics. Alpine foliation dips and becomes steeper and more intense to the south (Trümpy 1980). Alpine metamorphism increases southwards (Masson 1980) to greenschist facies (Keller 1999).

The SAG is mostly composed of granitic gneiss with quartz, feldspar and low to moderate (5-25\%) mica content (Keller 1999) making up the major mineralogical components. The fabric varies from granitoid to intensely foliated schist on a scale from one metre to several tens of metres

\subsection{Geomechanical characterisation of a Subsection of the Southern Aar Granite}

The 100 metre long tunnel section being characterisaed is located at the southern boundary of the SAG and is composed of unfoliated granite with abundant quartz and low mica content, as well as moderately to highly foliated schist with nearly equal quartz and feldspar content, and medium mica content. This section was selected due to its geological and mechanical variability, as well as the availability of $5 \mathrm{~cm}$ diameter drill core samples at one metre spacing. Figure 6 is a compilation of mapping of the tunnel wall, division into geological domains, point load (PLT) index strength data and the values resulting from the characterisation of the thin sections.

On the tunnel-wall maps, macro geological features such as shears and fractures, as well as distinct changes in rock type were recorded, supplemented by locations of overbreak and spalling. Of particular interest are sections of higher quartz content with corresponding lack of fabric, which manifest themselves as several metre wide zones or centimeter wide veins. Using the drill core samples and tunnel wall map records the geology along the section was classified into the dimensionless domains, outlined in Table 2, using the following criteria: mineralogical components, median grain size, grain size distribution, fabric type and overall variability, in terms of shear zones, fractures, rock type and tunnel wall overbreak.

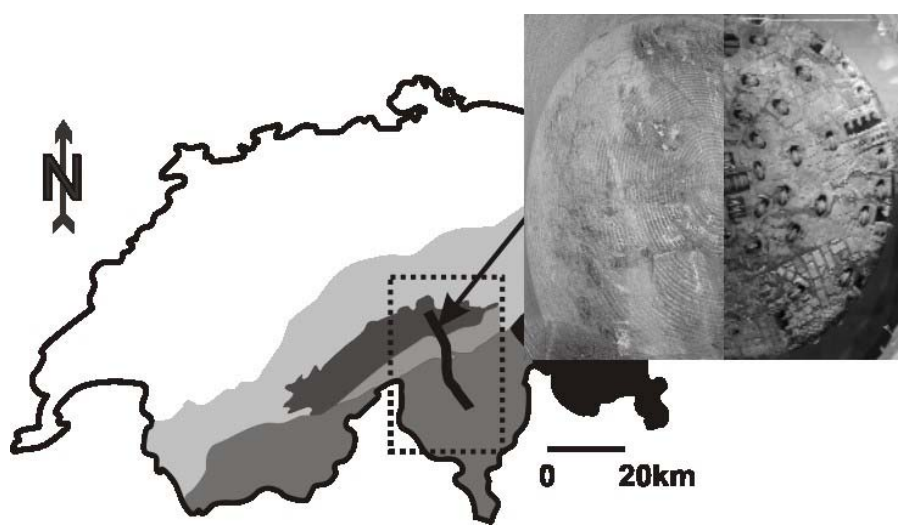

Figure 4. Map of Switzerland showing Gotthard tunnel location outlined in dashed box, Alps shown in shaded areas. Modified from Schweizerischen Geologischen Kommission.

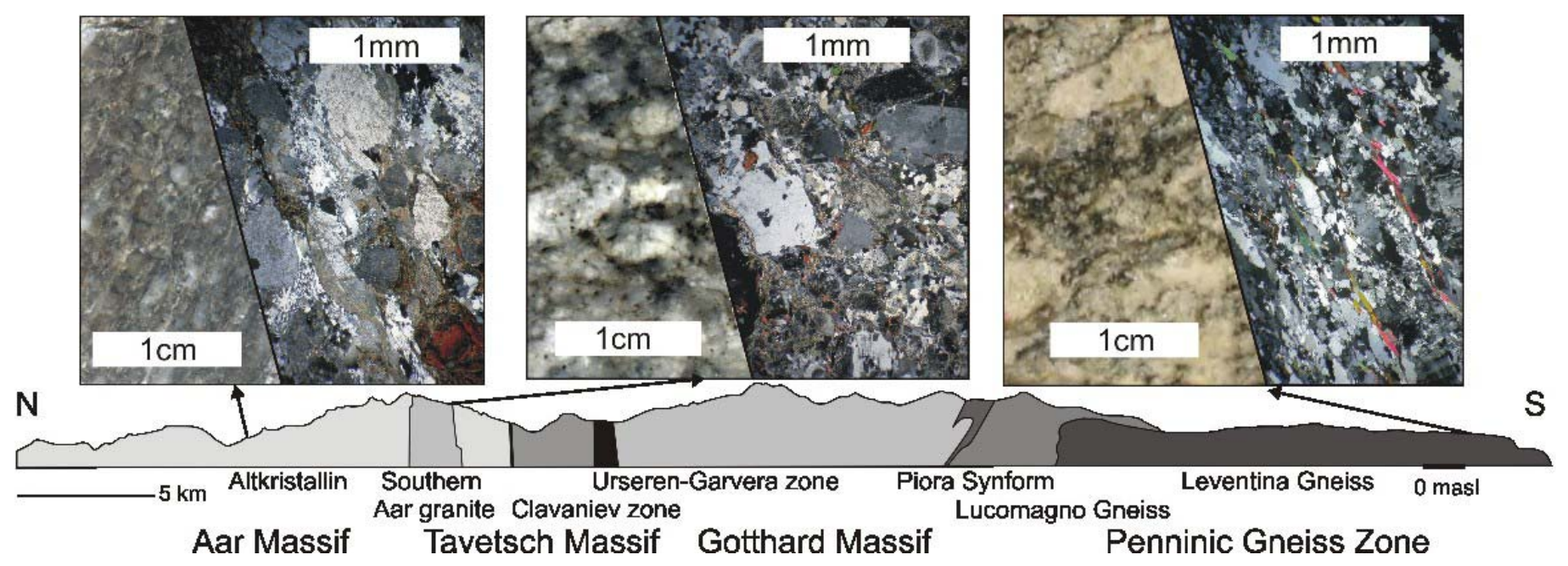

Figure 5. Geological cross section through the major units of the Gotthard Base Tunnel (after Keller 1999). Southern Aar Granite shaded at southern end of the Aar Massif. Vertical scale same as horizontal scale. Representative hand sample photos (on left) and photomicrographs (on right) associated with three locations along the Gotthard Base Tunnel transect. 


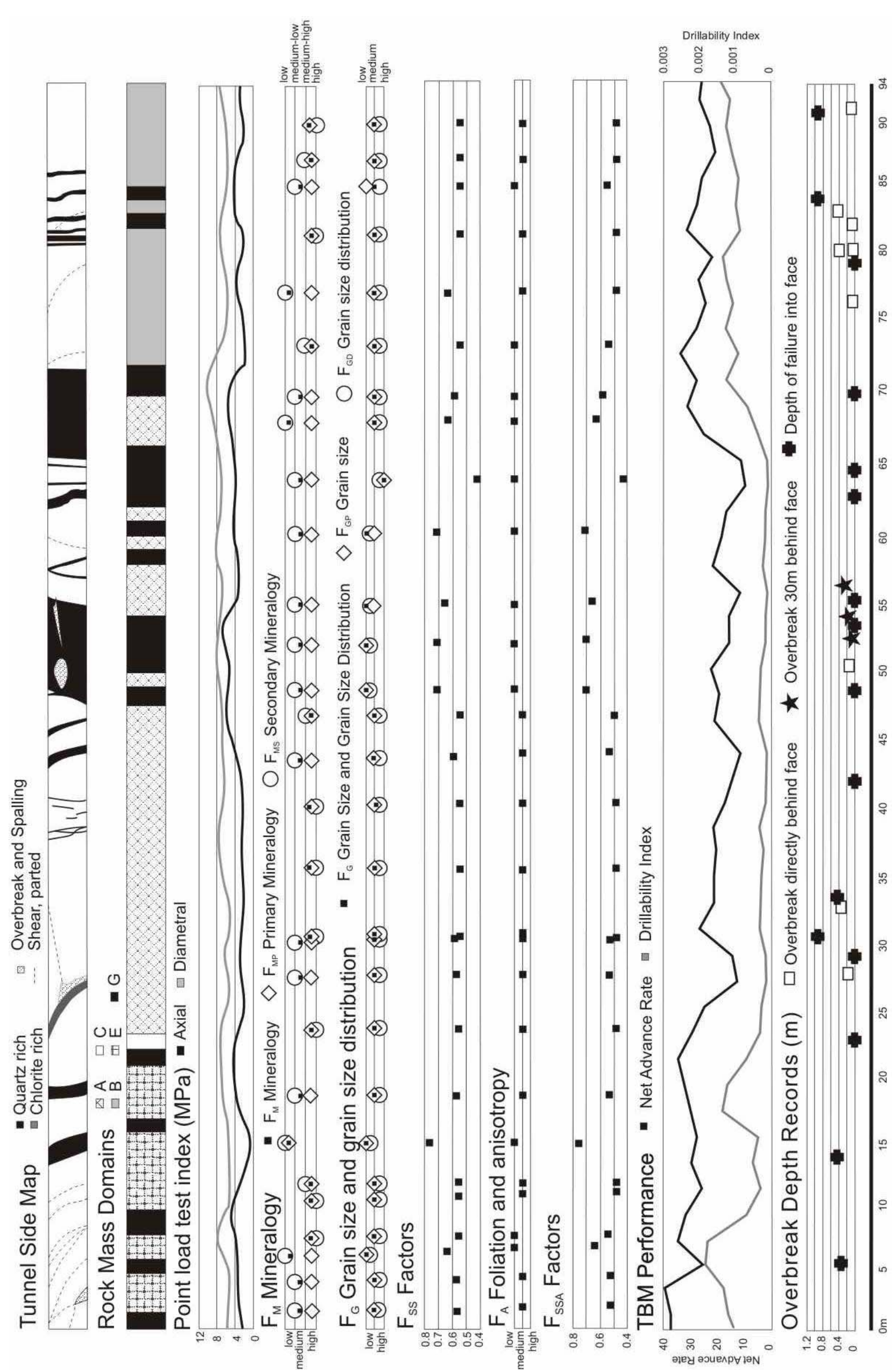

Figure 6. Cross-sectional compilation of tunnel wall mapping data, rock mass domain classification, point load index strength $(2 \mathrm{~m}$ central average), $\mathrm{F}_{\mathrm{M}}, \mathrm{F}_{\mathrm{G}}, \mathrm{F}_{\mathrm{SS}}, \mathrm{F}_{\mathrm{A}}$, and $\mathrm{F}_{\mathrm{SSA}}$ factors, TBM performance (NAR and DI values, on a per stroke (2m) frequency) and overbreak record data. 
Table 2. Description of geological domains from Figure 6

\begin{tabular}{|c|c|}
\hline Domain & Description \\
\hline$\overline{\mathrm{A}}$ & $\begin{array}{l}>10 \text { metre scale variability with feldspar, quartz and } \\
\text { mica, in decreasing percentage, medium }(0.5-5 \mathrm{~mm}) \\
\text { grain size and fabric ranging from preferred } \\
\text { orientation of feldspars to schistosity defined by } \\
\text { micas, no spalling }\end{array}$ \\
\hline B & $\begin{array}{l}>10 \text { metre scale variability with feldspar, quartz and } \\
\text { mica, in decreasing percentage, medium }(0.5-5 \mathrm{~mm}) \\
\text { grain size and fabric consisting of schistosity defined } \\
\text { by micas, approximately } 5 \% \text { spalling }\end{array}$ \\
\hline $\mathrm{C}$ & $\begin{array}{l}>10 \text { metre scale variability with feldspar, quartz and } \\
\text { mica (up to } 30 \%) \text {, in decreasing percentage, small } \\
(<0.5 \mathrm{~mm}) \text { grain size and fabric consisting of } \\
\text { continuous cleavage defined by micas, nearly } 30 \% \text { of } \\
\text { area contains spalling (spalling not shown in Figure } 6 \text { ) }\end{array}$ \\
\hline $\mathrm{E}$ & $\begin{array}{l}\text { Less than decameter scale variability with feldspar, } \\
\text { quartz and mica (high variability from } 2-25 \% \text { ), in } \\
\text { decreasing percentage, medium }(0.5-5 \mathrm{~mm}) \text { grain size, } \\
\text { with micas often }<0.5 \mathrm{~mm} \text { and feldspars often }>5 \mathrm{~mm} \text {, } \\
\text { and fabric ranging from preferred orientation of } \\
\text { feldspars to schistosity defined by micas to cleavage } \\
\text { defined by micas in narrow shear zones, } 10-25 \% \text { of } \\
\text { mapped area contains spalling (spalling not shown in } \\
\text { Figure } 6 \text { ) }\end{array}$ \\
\hline G & $\begin{array}{l}>10 \text { metre scale variability with feldspar and quartz } \\
\text { (mica only } \sim 2 \% \text { ), medium }(0.5-5 \mathrm{~mm}) \text { grain size and } \\
\text { no fabric, no spalling and infrequent shear zones }\end{array}$ \\
\hline
\end{tabular}

* note that domains D and F are not shown in Figure 6

Thin sections were cut from the drill core samples, which had previously been strength tested with a point load testing apparatus, for which results are shown in Figure 6. The thin sectioned samples were characterised according to the scheme shown in Figure 3. The values assigned to $\mathrm{F}_{\mathrm{M}}, \mathrm{F}_{\mathrm{GS}}$, and $\mathrm{F}_{\mathrm{A}}$, and their combinations, $F_{S S}$ and $F_{S S A}$, are shown in separate graphs in Figure 6.

\subsection{Geomechanical Characterisation and its Relation to Encountered Geology}

The rock mass domain classification correlates well to the geology recorded in the tunnel wall map in Figure 6. Some mismatch exists due to the heterogeneity of the rock types, the orientation of their boundaries in relation to the orientation of the drill core (roughly 6 degrees to horizontal) and the resolution of the drill core diameter. Domain $G$ corresponds to zones of quartz-rich rock in the tunnel wall map, domain E corresponds to low shear zone spacing, domain A corresponds to rare shear zone occurrences and domain B corresponds well to sporadic shear zone occurrences.

A few trends in the characterisation factors can be observed. The higher the $\mathrm{F}_{\mathrm{SS}}$ value, the lower the spall-behaviour potential of the rock, and vice versa. The higher $F_{\text {SS }}$ values correspond to domains $A$ and $\mathrm{G}$, with one high $\mathrm{F}_{\mathrm{SS}}$ in domain $\mathrm{E}(14 \mathrm{~m})$. The medium to low $\mathrm{F}_{\mathrm{SS}}$ values correspond to domains $\mathrm{A}$, $\mathrm{B}$ and $\mathrm{E}$. One occurrence of low $\mathrm{F}_{\mathrm{SS}}$ corresponds to domain $G(63 \mathrm{~m})$, but this is a very coarse grained sample of limited extent.
Similarly, the higher the $\mathrm{F}_{\mathrm{SSA}}$ factor, with the impact of foliation taken into consideration, the lower the spalling potential. A large number of the samples in the tunnel area in Figure 6 correspond to domain $G$ or are samples that have no or poorly developed foliation, and $\mathrm{F}_{\mathrm{SSA}}$ is the same as $\mathrm{F}_{\mathrm{SS}}$, but the samples that do have foliation and have a decreased $\mathrm{F}_{\mathrm{SSA}}$ correspond to domains $\mathrm{A}, \mathrm{B}$ and $\mathrm{E}$, which are generally characterised as having well developed foliation.

A comparison of the domains and the PLT index strength shows a correlation between degree of variability and the domain: highly variable domain $\mathrm{E}$ also exhibits high variability in the PLT, the same is true to a lesser extent for domain $\mathrm{B}$, the variability is low for low variability domain A, while the PLT is homogeneously higher for domain $\mathrm{G}$.

\subsection{Geomechanical Characterisation and its Relation to Geological History}

The domain and geological factor characterisation of the focus area in Figure 6 demonstrates both homogeneity and heterogeneity in the rock unit. Most of the domains are selected based on broad homogeneity of characteristics such as mineralogy, texture and macro features, while domain $\mathrm{E}$ is selected based on its heterogeneity. In general, however, all of the domains have similar mineralogy (mainly composed of varying percentages of feldspar, quartz and mica, in decreasing order) and grain size (small to medium). The foliation varies slightly between alignment of feldspars, schistosity defined by mica, and decimeter scale shear zones with continuous cleavage (non-parted), with domain G lacking foliation.

The geological description from section 4.1 is very similar to the domain descriptions in this zone. The domains capture the geological descriptions written by geologists for tender purposes, while at the same time distinguishing boundaries between zones with slightly different characteristics. In addition, the domains and geological factor characterisation highlight the different geological characteristics that impact the rock behaviour during TBM excavation.

\section{RELATION OF GEOMECHANICAL CHARACTERISATION TO ENGINEERING PROCESSES}

\subsection{Examination of TBM performance}

Engineering data were collected from the geological section described in section 4. TBM performance data were collected from the TBM used to excavate the northern section of the GBT, at a depth of approximately $2000 \mathrm{~m}$. Figure 7 shows the relationship between the penetration rate 
$(\mathrm{mm} /$ revolution), the gross machine thrust $(\mathrm{kN})$ and the net advance rate (single TBM stroke distance normalized by active tunnelling time, during which the head was turning, in $\mathrm{mm} / \mathrm{min}$ ). The net advance rate can reflect decreases to advance resulting from either low penetrability or face instability. In addition to TBM data, location and magnitude of overbreak at the tunnel wall and records of tunnel face overbreak are also shown in Figure 6.

\subsection{Application of Geomechanical Characterisation Scheme to TBM Excavation}

Keller (1999) states that it is difficult to determine where spalling is likely to happen in the tunnel section. Domains for macro characteristics and geological factors for micro characteristics can be used to interpret the rock behaviour during TBM excavation. By looking only at the PLT data in Figure 6, zones with negatively impacted advance rate should correspond to low PLT index strength, but this is untrue around $15 \mathrm{~m}$, while a comparison of PLT data and overbreak data shows a good correspondence between index strength and magnitude of overbreak.

When PLT and FSA $_{\text {SSA }}$ are observed simultaneously (as an approximation for generating $\mathrm{F}_{\mathrm{FG}}$ ) and compared to the TBM relationships and overbreak records, a pattern emerges in which combinations of low PLT index strength but high $\mathrm{F}_{\mathrm{SSA}}$, such as at $15 \mathrm{~m}$, or combinations of low PLT index strength and low $F_{\mathrm{SSA}}$, such as at $30-35 \mathrm{~m}$, can result in minor overbreak in the tunnel face that does not negatively impact the rock toughness, while combinations of high PLT index strength and high $\mathrm{F}_{\mathrm{SSA}}$, such as at 53-58m, can lead to stable face conditions but sudden delayed wall overbreak once the face has progressed some distance away from this area. Combinations of moderate PLT index strength and low to moderate $F_{S S A}$, such as at $77-81 \mathrm{~m}$, can lead to face instability with negative impact on TBM advance.

When analyzing this data, an understanding of the spatial extent of rock types is necessary to interpret the impact on rock behaviour during TBM excavation. For example, a low $\mathrm{F}_{\mathrm{SS}}$ resulting from large grain size in the unfoliated rock from domain $\mathrm{G}(63 \mathrm{~m})$ would suggest high spall potential, but no evidence of face or tunnel wall instability exists. The extent of this grain size extreme is less than 2 metres and did not impact the behaviour enough to affect the TBM performance relationship in this area. A rock domain with high variability at TBM scale (such as domain B), in particular in terms of spall sensitivity and strength, will lead to higher magnitude of face instability and neutral to negative impact on TBM advance, while a rock with low heterogeneity in strength and spall sensitivity (such as domain $\mathrm{G}$ ) will lead to homogeneous impact on

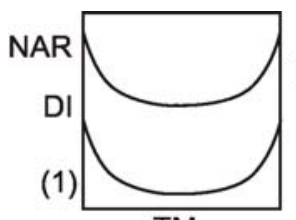

TM

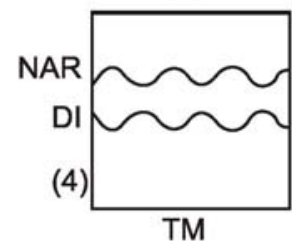

TM

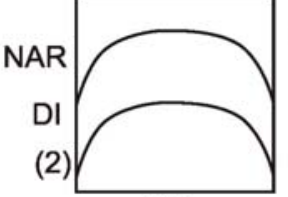

TM

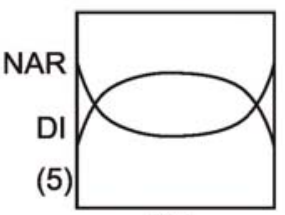

TM

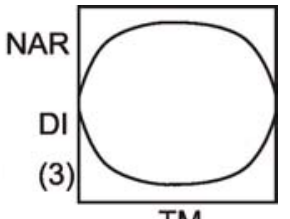

TM

Figure 7. TBM performance relationships between the drillability index (DI = penetration rate/ gross thrust, proxy for penetrability) and the net advance rate $(\mathrm{NAR}=$ distance excavated/ active excavation time), TM is tunnel metre. 1 represents low penetrability resulting in low net advance rate; 2 represents improved penetrability and net advance rate; 3 represents low penetrability but resulting high net advance rate; 4 represents variable, opposing moderate penetrability and net advance rate trends; 5 (not shown in Figure 6) represents high penetrability but low resulting net advance rate, in this rock unit this is due to face instability.

TBM advance. In the case of domain $G$ the impact is negative due to unfavourable combinations of high strength and low spall sensitivity, but the contrary is possible with favourable combinations of moderatehigh strength and moderate spall sensitivity.

\section{CONCLUSIONS AND FUTURE WORK}

When designing the excavation and support methodology for TBM tunnelling it is critical to make appropriate predictions for rock behaviour and response based on the geological data available. The interpretations presented here are used to demonstrate the basis for the development of a geomechanical characterization scheme used to predict spalling sensitivity and fracture potential at the tunnel face. This scheme is a two-fold approach considering micro scale features such as mineralogy and texture as well as macro scale features such as scale of rock type variability and was illustrated with an application to a $100 \mathrm{~m}$ long tunnel segment excavated by TBM.

The ability of the geomechanical characterisation to capture the geological description was demonstrated by comparing it to tunnel wall maps and geological descriptions of the SAG rock unit. Some preliminary relationships between the characterisation and the rock behaviour during excavation were also demonstrated with TBM data and tunnel wall and face overbreak records. Further calibration of the geomechanical characterisation scheme aims to refine the quantitative approach for relating geology to TBM performance.

The discussion surrounding Figure 6 also demonstrates the need for attention when employing 
the geomechanical characterisation methodology during site investigation. Geological descriptions should contain appropriate information to determine different domains based on geological features and degree of variability. Within each domain representative samples should be selected for geological factors characterisation. In addition, if samples exhibiting extreme characteristics with respect to the domain are selected for geological factors characterisation, then the scale and frequency of the extreme geology should be taken into account when associating it to rock behaviour during TBM excavation.

The quantification and classification of geological characteristics for rock behaviour prediction has been illustrated at the micro to several metres scale. In situations where detailed data is unavailable the geological description may be on the rock unit (100's of metres) scale. Future work will address the development of a methodology for combining the benefits of domain and geological factor characterisation at various scales, from $\mathrm{mm}$ scale in thin sections to 100's of metres from rock unit descriptions, into a meaningful system applicable at the TBM scale.

\section{ACKNOWLEDGEMENTS}

Financial and technical support provided by Herrenknecht AG. Financial support also provided by a Postgraduate Scholarship from the Natural Science and Engineering Research Council (NSERC) of Canada. The authors would like to thank Mr. Scheifele and Mr. Eggel from Herrenknecht Schweiz, Mr. Holzhuber from AGN, Mr. Bertholet and Dr. Weh from MaTrans, and Mr. Classen and Mr. Ghirlanda from TAT for their support during data collection, and Prof. Löw at ETH Zürich for help obtaining testing equipment.

\section{REFERENCES}

Barton, N. 2000. TBM Tunnelling in Jointed and Faulted Rock. Rotterdam: Balkema.

Barton, N., Lien, R., and Lunde, J. 1974. Engineering classification of rock masses for the design of tunnel support. Rock Mechanics 6(4):189-239.

Bieniawski, Z.T. 1989. Engineering Rock Mass Classifications. New York: Wiley.

Bonzanigo, L., and Opizzi, P. 2005. Low angle fault zones and TBM excavation in Bodio section of Gotthard Base Tunnel. In Löw, S. (ed.), Geologie und Geotechnik der Basistunnels am Gotthard und am Lötschberg: 155-165. Zürich: vdf Hochschulverlag AG and der ETH Zürich.

Bruland, A. 1998. Hard rock tunnel boring Design and construction [Ph.D. thesis]. Trondheim: Norwegian Technical University.

Büchi, E. 1988. Einfluss Geologischer Parameter auf die Vortriebsleistung einer Tunnelbohrmachine [Ph.D. thesis]. Universität Bern.
Burkhard, M., and Isler, A. 2005. Structural Geology of the Aarmassif and the significance of the new Carboniferous graben in the Gasterngranite. In Löw, S. (ed.), GEAT05 Symposium Geologie Alptransit Abstracts : 43. Zürich.

CERCHAR - Centre d'Etudes et de Recherches de Charbonnages de France. 1986. The CERCHAR abrasiveness index.:12-Verneuil.

Chopin, M. 2005. Abdichtungen der Sedimenteinschuppungen am Fusspunkt Ferden. In Löw, S. (ed.), GEAT05 Symposium Geologie Alptransit Abstracts : 45. Zürich.

Diederichs, M.S., Kaiser, P.K., Eberhardt, E. 2004. Damage initiation and propagation in hard rock during tunnelling and the influence of near-face stress rotation. Int. Jour. Rock Mech. Min. Sci. 41(5):785-812.

Dollinger, G.L., Handewith, H.J., and Breeds, C.D. 1999. Use of the Punch Test for Estimating TBM Performance. Tunnelling and Underground Space Tech. 13(4):403-408.

Frei, B., and Breitenmoser, T. 2005. Geologisch-geotechnische und hydrologische Verhältnisse um Vortrieb Amsteg: Vergleich zwischen Prognose und Befund. In Löw, S. (ed.), Geologie und Geotechnik der Basistunnels am Gotthard und Lötschberg: 101-118. Zürich: vdf Hochschulverlag AG and der ETH Zürich.

Hoek, E. 1999. Putting Numbers to Geology - an Engineers Viewpoint. Q. Jour. Engr. Geol. Hydrogeol. 32(1):1-19.

Illston, J.M., Dinwoodie, J.M., and Smith, A.A. 1979. Concrete, Timber and Metals The Nature and Behaviour of Structural Materials. Wokingham, Great Britain: Van Nostrand Reinhold Co. Ltd.

Kaiser, P.K. 2005. Tunnel stability in highly stressed, brittle ground - rock mechanics considerations for Alpine tunnelling. In Löw, S. (ed.), Geologie und Geotechnik der Basistunnels am Gotthard und am Lötschberg: 183-202. Zürich: vdf Hochschulverlag AG and der ETH Zürich.

Keller, F. 1999. Geologischer Bericht: Geologie, Geotechnik und Hydrologie. AlpTransit.

Masson, H. 1980. Helvetic Alps of Western Switzerland. In Trumpy, R. (ed.), Switzerland An Outline of the Geology of Switzerland, Publications of the 26th International Congress, Paris.

Nicolas, A., and Poirier, J.P. 1976. Crystalline Plasticity and Solid State Flow in Metamorphic Rocks. Bristol, Great Britain: John Wiley \& Sons.

Plinninger, R., Käsling, H., Thuro, K., and Spaun, G. 2003. Testing conditions and geomechanical properties influencing the CERCHAR abrasiveness index (CAI) value. Int. Jour. Rock Mech. Min. Sci. 40:259-263.

Rostami, J., Gertsch, R., and Gertsch, L. 2002. Rock fragmentation by disc cutter: a critical review and an update. Proc NARMS-TAC 2002, Eds. Hammah et al. Toronto, Canada. 2002.

Rostami, J., Ozdemir, L., and Nilsen, B. 1996. Comparison between CSM and NTH Hard Rock TBM Performance Prediction Models. In Proceedings of the Annual Technical Meeting: Institute of Shaft Drilling Technologys, Las Vegas, USA., 1996.

Sapigni, M., Berti, M., Busillo, A., and Cardone, G. 2002. TBM performance estimation using rock mass classifications. Int. Jour. Rock Mech. Min. Sci. 39:771-788.

Schweizerischen Geologischen Kommission. 1980. Tektonische Karte der Schweiz.

Trümpy, R (Ed). 1980. Switzerland An Outline of the Geology of Switzerland, Pubilcations of the 26th International Geological Congress, Paris.

Zhang, Z.X., Kou, S.Q., and Lindqvist, P.-. 2003. In-situ Measurements of Cutter Forces on Boring Machine at Äspö Hard Rock Labratory Part II. Characteristics of Cutter Forces and Examination of Cracks Generated. Rock Mech. Rock Engr. 36(1):63-83. 